Artigo original

\title{
TENDENCIAS PEDAGOGICAS Y POSTMODERNIDAD
}

Hilda M. F. MONTYSUMA ${ }^{1}$ Landelino Sierra PACHECO ${ }^{2}$

La discusión sobre la postmodernidad surge hacia fines de los 70 e inicios de los 80 , lo que no significa que no haya estado presente en los debates teóricos en el campo de las ciencias sociales, y en cierta medida fue trasladándose a otras esferas del conocimiento. El presente trabajo tiene la pretensión de hacer una aproximación al fenómeno de la discusión postmoderna y su imbricación con la esfera de la educación y las tendencias pedagógicas resultantes de ese modo de pensar la realidad social del presente.

Se hace una valoración de las diferentes interpretaciones del pensamiento postmoderno y su importancia para conformar una línea de acción vinculada al desarrollo de la ciencia y la tecnología, y por consiguiente como se concibe a partir de evaluar la realidad, función y/o encargo social de la educación.

El modelo económico-social sustentado en las teorías de Ford y Keynes, en las que la centralización, eficiencia, control, dirección y ganancia eran el modus operandi de la expansión imperialista no daba respuesta a los cambios que emanaban de la evolución de la producción capitalista. Ese modelo rígido no daba posibilidades de variar a tenor con los cambios que surgían del desarrollo de la base técnico-material de la producción capitalista. El liberalismo clásico. En el plano económico, político y social se tornó obsoleto, comenzó a desarrollar, por tanto, una nueva forma para hacerse factible, considerando que el capital en los marcos nacionales no tenía posibilidades de garantizar la dinámica de desarrollo, busca su expansión fuera de las fronteras nacionales, procurando vías no tradicionales que le permitiera la acumulación flexible del capital. De este modo introdujeron modificaciones en los procesos y el mercado de trabajo, se crearon nuevos productos y nuevas formas de organización de las empresas. Sobre todo, el nuevo régimen de acumulación necesitaba una "comprensión" diferente del tiempo y del espacio, a partir de la expansión de las comunicaciones y el bajo costo del transporte, que permiten una creciente rapidez en la toma de decisiones.

${ }^{1}$ Professora do Instituto Superior de Educação de Roraima. Dra. em Ciências da Educação E-mail: hildamonty@aol.com

${ }^{2}$ Profesor Titular del Departamento de Ciencias Sociales de la Universidad "Camilo Cienfuegos" de Matanzas-Cuba en el área de Filosofía y Teoría Política. Dr. en Filosofia. E-mail: sierra@cdict.umtz.edu.cu

Bol. Mus. Integrado de Roraima, Boa Vista 6:25-30. 2000[2007] 
El capital tiene posibilidad hoy de ser más flexible y de moverse de forma más rápida, lo que conlleva a enfatizar lo nuevo, lo efímero y lo contingente. Estos paradigmas son esencialmente distintos a los que sustentaban los modelos FordistasKeynesiano, que hacían énfasis en el largo plazo, en el mercado establecido y estructurado de forma rígida. Los cambios trascienden a todas las esferas de la actividad social. En este escenario surgen diversas valoraciones y corrientes de pensamiento que dirigen su atención a la pluralidad, las diferencias, como principios rectores de la cultura, la cosmovisión filosófica, educacional y al análisis social en general. Puede afirmarse que en estas condiciones el capitalismo impone una lógica de pensamiento. La producción espiritual ha pasado a integrarse a la producción general de mercancías bajo el nuevo modelo flexible de acumulación. Ello contradice el paradigma de la modernidad que concebía el progreso social de forma lineal, la planificación a largo plazo y la estandarización y homogeneización del pensamiento. Estas concepciones proponen como nuevos valores la fragmentación, la desconfianza a los discursos totalizadores. La modernidad es concebida ahora como positivaracionalista, tecnocrática, etc. Estas ideas toman cuerpo en el desarrollo de un paradigma " cultural nuevo".

La nueva tendencia de pensamiento recibe la etiqueta de Postmodernidad. ¿Qué es la postmodernidad? No existe una respuesta fácil, según Ravelo Cabrera (Monal, Isabel et alii 1998: 420-447) existen cuatro interpretaciones de lo postmoderno. La primera es la que proviene de $\mathrm{J}$. Jabermas; de acuerdo con la teoría crítica restauracionista alemana, el discurso postmoderno es una reacción antimoderna, que centra su atención fundamentalmente, en la falta de conexión entre las concepciones iluministas de la modernidad.

La segunda interpretación es del pensador francés J. F. Lyotard, que "celebra la postmodernidad como la era lúcida de la sospecha frente a los discursos modernos legitimadores de la razón. La "condición postmoderna" es la incredubilidad frente a los "metarrelatos" universalistas y totalizadores de la modernidad" (In: Ravelo Cabrera, 1998: 444. Se percibe una incredubilidad ante los discursos homogéneos y totalizadores frente al pluralismo de ideas y cultura. El consenso es sustituido por el disenso, pues todo es relativo.

La tercera interpretación viene del italiano G. Vattimo, que discrepa de Habermas y Lyotard- su forma legitimadora de la historia. Para Vattimo, lo postmoderno no representa la trascendencia de los relatos -de Lyotard-, tampoco la comunicación ilimitada - de Habermas -, sino el nihilismo nietzscheano. Existe un caos en la comunicación limitada, por lo que la historia sólo es posible a partir de una interpretación hermeneútica considerando la relatividad de los valores. El fin de al modernidad está intimamente relacionada con el fin de la historia o su negación. Está "si decide ser completa, servirá para sonrojarnos o par orgullecernos, más com un espejo que como un instrumento de edificación del presente y el futuro" (Ichikawa, Morín, 1998: 54), apoyado en esa concepción, la interpretación de la historia presente determina en la de historia futura. La explicación postmoderna de Vattimo está relacionada a la idea de que la historia no es unidireccional ni finalista.

Una de las premisas del fin de la historia es que el mundo es incognoscible, por sus constantes cambios, y cualquier interpretación que esté relacionada a la interpretación, según la concepción nihilista, en su esencia, es falsa.

El cuarto modelo es del marxista norteamericano F. Jamerson. Es innegable que se pasa por un momento de cambios de estilos que se asocian con las transformaciones de la sociedad capitalista. Para Jamerson existe una nueva lógica cultural dominante que mantiene relación con el consumismo masificado del capitalismo imperialista.

Jamerson establece algunas características de la postmodernidad: "el populismo estético de las culturas de masas y el kitsch, la desconstrucción de la expresión del ser y toda su axiomática sustancialista, el debilitamiento de al historicidad, el hegemonismo de al cultura de la imagen, 
Tendencias pedagogicas y postmodernidad...

la mengua de los afectos que acompaña a un nuevo tipo de emocionalidad espiritual, la sustitución de la parodia por el pastiche (la trasgresión por la conformidad), la eliminación de la historia por el "historicismo2 o localismo..." (Ravelo Cabrera, 1998: 446) Ese conjunto de particularidades Según $H$. Foster(in op. Cit.) ha engendrado una sociedad del tipo postindustrial en que la nueva lógica cultural es de consumo masificado que imponen las nuevas leyes del sistema capitalista.

Existe una relación íntima de lo moderno con lo postmoderno y a partir de los 50, época en que por convención se encierra el modernismo; pero lo "post" no significa necesariamente que hubo una ruptura total, porque no puede desligarse el pasado, incluso para aquellos que defienden "el fin de la historia". La modernidad, en su sentido lato, significa actual, nuevo, que se opone a lo viejo y arcaico, de manera que el pensamiento postmoderno no podría ser la sencilla ruptura o negación de lo moderno. Existe una articulación de lo moderno y lo post, "cada época tiene su propio modernismo" (Ibíd. p. 426.

Según Gadotti (1998: 310-313), la postmodernidad es un movimiento de indagación sobre el futuro, que se revela no sólo por la forma de uso de la tecnología, sino también en todas las áreas del conocimiento como las artes, la economía, la sociología, la educación, etc.

En cuanto a los sistemas instructivos. La tendencia tecnicista -propia de la modernidad- estipula la enseñanza como un proceso de condicionamiento por medio del uso del estimulo respecto a las respuestas que se desea obtener. De esa manera, los sistemas de instrucción apuntan hacia el control del comportamiento individual ante los objetivos preestablecidos. Se trata de un enfoque directivo de la enseñanza, centrado en el registro de las relaciones. El profesor es entendido como un administrador que ejecutará lo planificado y el alumno será moldeado de acuerdo con la demanda del mercado.

En la postmodernidad o nuevo tecnicismo, la automatización y la información, consecuencias de la tecnología electrónica de alta resolución, conlleva a una cierta pérdida de la identidad de las individuos, o su desintegración. En la educación surge una crisis de paradigmas. Es decir, tener una visión del "conjunto", sin perder lo singular de los hechos o los acontecimientos. Se manifiesta una gran contradicción en lo concerniente a precisar lo especificamente multicultural y lo individual y/o regional; que ha posibilitado la exaltación de posiciones extremas como por ejemplo la xenofobia.

La tendencia educacional neotecnicista o postmoderna a pesar de estar dirigida a la formación tecnológica, forma también a un hombre más preocupado por la individualidad, la equidad, sin eliminar las diferencias, evaluación (en ese mismo orden), la neotecnicista hace énfasis en lo afectivo, la interrelación, la autodeterminación personal. Ese modelo de educación exige un nuevo tipo de profesor, que esté interesado en las individualidades culturales y sociales, por lo que debe trabajar mucho más con el significado que con el propio contenido en sí.

Los objetivos educacionales no son establecidos en términos de logros de la racionalidad, sino de finalidad educacional en dirección de formar un ciudadano creativo y preocupado con su entorno. La escuela tiene la responsabilidad de ser autónoma, de vanguardia, generadora de científicos y de pluralismo cultural. Ya no es suficiente calificar técnicamente al hombre, es necesario formar competencias, el nuevo modelo económico necesita de personas creativas, éticas, preocupadas por la gestión social y por el entorno medio ambiental.

La competitividad internacional necesita de un trabajador comprometido con el propio proceso de producción, que se sienta responsable por el desarrollo de nuevas tecnologías. Ese nuevo perfil de hombre debe ser logrado por medio de la educación; no es que a ella quepa toda la responsabilidad, pero seguramente tendrá que ser involucrada en ese objetivo. Como la globalización, forma por la cual se ejecuta la política neoliberal, está íntimamente interesada en la educación, se arriesga a algunas hipótesis en relación con el papel que la escuela 
desempeña en una concepción postmoderna o neotecnicista:

1.La enseñanza básica y técnica estará bajo la mirada del capital por su importancia en la preparación del nuevo trabajador. Ya no es suficiente sólo la calificación de mano de obra, es necesaria una formación más integral y humanista. La didáctica y las metodologías de enseñanzas especificas (en especial la de alfabetización y la de matemátical serán objeto de evaluación sistemática sobre la base de los resultados (aprobación que generan.

2.La "nueva escuela" necesitará de una "nueva didáctica", la que exigirá también un "nuevo profesor" - todos alineados con las necesidades de un "nuevo trabajador".

3. Tanto la didáctica como la formación del profesor tendrá un énfasis muy grande en lo "operacional" y en los "resultados" - la didáctica podrá limitarse cada vez más al estudio de los métodos específicos para enseñar determinados contenidos considerados prioritarios, y la formación del profesor podrá ser aligerada desde el punto de vista teórico. Dando lugar a la formación de un "práctico", en el sentido de buscar lo fundamental que debe ser enseñado; será progresiva la adopción del modelo de enseñanza modular. De forma creciente se exalta la psicologización de la enseñanza así como las habilidades administrativas.

4.Los determinantes sociales de la educación y el debate ideológico podrán ser considerados secundarios. De esa forma se verifica un estadio de desilusión; el entusiasmo y el colectivismo que caracterizaron los movimientos populares de la década de los 50/ 60 , son sustituidos por 1 a individualidad y falta de creencia, casi de forma general, en las organizaciones políticas y sociales y de clase.

5. La privatización gradual de la educación. La política neoliberal presupone la ausencia del Estado, por lo menos como regulador del mercado, y en esa perspectiva la escuela es considerada como una empresa que debe atender a una demanda de mercado y ser regulada por él.

6. LA escuela debe no solamente responder a la demanda del mercado, sino también, a la vez, debe generar demandas, como, por ejemplo, la creación de software educativos.

7. La educación se encuentra en una encrucijada, sin una alternativa practicable con garantía de éxito; negar el postmodernismo es padecer de miopía y entregarse totalmente a él también lo es. La única alternativa que se presenta es el debate, pues la crisis no es apocalíptica, presenta aspectos positivos y negativos. La postmodernidad no es buena ni mala por sí sola; entraña retos culturales, sociales, económicos, educacionales, políticos, éticos, etc.

8.En las últimas décadas del siglo $\mathrm{XX}$, el debate sobre la ética se ha reavivado de forma más contundente. En un mercado cambiante las empresas no tienen seguridad de futuro, pero tienen que mantenerse en una posición ética, además de rendir un sentido para su existencia, pues los consumidores han demostrado que prefieren productos de empresas que actúan éticamente y tienen preocupación por el entorno social. Se han producido acciones dirigidas a la denuncia de empresas con marcas comerciales reconocidas mundialmente, por no atender a las condiciones adecuadas de trabajo en filiales fuera del territorio de su casa matriz. Así, por ejemplo, la NIKE y la REEBOK, entre otros, vieron disminuidas el valor de sus acciones en el mercado, siendo obligadas a una reestructuración de su política administrativa.

De lo expuesto anteriormente pueden hacerse algunas valoraciones. La postmodernidad o neotecnicismo no tiene una sistematización teórica lo suficientemente coherente y genuina; las ideas expuestas con respecto a su imbricación con las teorías pedagógicas siguen la lógica del paradigma construido por el desarrollo del modelo de producción capitalista contemporáneo, que necesita una 
Tendencias pedagogicas y postmodernidad...

sustentación teórica que permita a la práctica de este sistema aparecer como la "nueva lógica" global.

La postmodernidad se ha manifestado bajo dos caras: una negativa - que se traduce en crítica destructiva de valores que han estado vigentes hasta el momento, la desorientación hacia donde sigue la sociedad, una sensación que de que todo está acabado; otra positiva -es la antitesis de la anterior, que se encuentra exactamente en la búsqueda de cómo superar la crisis de los valores que está pasando la sociedad contemporánea. Es la reflexión sobre la propia existencia humana y realización personal, la esperanza, la búsqueda por la calidad de vida. La lucha por el derecho a la manifestación de la pluralidad cultural, específicamente hablando en Latinoamérica, la crítica, la imposición de las culturas occidentales.

En la educación se vislumbra el reconocimiento del papel de la formación, calificación y perfeccionamiento del profesional, principalmente del profesor considerando las necesidades del mercado. Además que la evaluación será considerada como un punto clave, sobre todo en lo que se refiere a la ordenación de recursos.

Tras el discurso postmodernista está un profundo miedo al socialismo y el propósito de evitar, a cualquier costo, la irremediable muerte de la sociedad burguesa.

\section{REFERENCIA BIBLIOGRÁFICA.}

CANO, L. Y GARCÍA, X. El postmodernismo: Esa fachada de vidrio, editorial de Ciencias Sociales, La Habana, 1994.

CASULLO, Nicolás (compilación y prólogo). El debate modernidad postmodernidad, $2^{\circ}$ edición, Editora Puntosur, Argentina, 1989.

FREITAS, Luis C. Crítica da organização do trabalho pedagógico e da didáctica, Editorial Pepirus, sao Paulo-Brasil, 1995.

GARCíA DE PORTAL, Jesús M. LA universidad latinoamericana: cultura de integración e identidad cultural, In: Revista Cubana de Educación Superior, Vol. 18, No 3 CEPES-Universidad d e La Habana, La Habana, 1998.

GADOTTI, Moacir. Historias das idéias pedagógicas, $6^{\circ}$ edición, Editora Ática, Série Educação, Sao PauloBrasil, 1998.

GUTIÉRREZ BARó, Elsa. Et alii. Modernidad-Postmodernidad. Editorial de Ciencias Sociales, La Habana, 1998.

GUADARRAMA GONZÁLEZ, Pablo. Humanismo $y$ postmodernidad. Editorial de Ciencias Sociales, La Habana, 1998.

GUADARRAMA GONZÁLEZ. P. Y PERELIGUIN, Nikolai. Lo universal y lo específico en la cultura. Universidad Central de Las VillasSanta Clara-Cuba, Universidad INCCA de Colombia, Bogotá-Colombia, 1998.

GUADARRAMA GONZÁLEZ, Pablo (coord.) et. alii. Filosofía en América Latina, editorial "Félix Varela", La Habana, 1998.

ICHIKAWA MARÍN, Emilio. La escritura $y$ el limite, Editorial Letras Cubanas, La Habana-Cuba, 1998.

Pensamiento

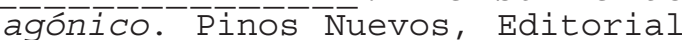
Ciencia sociales, La Habana, 1996.

LARRAín, Jorge. Postmodernismo e ideología. In: Estudios sociales $N^{\circ}$ 70, trimestre 04, La Habana, 1991 .

MATO, Daniel. (coord..) et alii. América Latina en tiempos de globalización: procesos culturales y transformaciones sociopolíticas. CRESAL/UNESCO, Caracas-Venezuela, 1996.

MAC LAREN, Peter. Contranarrativa, amnesia colonial e identidad de mestizaje: hacia una pedagogía crítica de la formación de la identidad postmoderna. CEPCE/Centro de Producción en Comunicación y Educación-Universidad Nacional

Bol. Mus. Integrado de Roraima, Boa Vista 6:25-30. 2000[2007] 
entre Ríos, Entre Ríos-Argentina, 1992 .

PACHECO, M. Elisa y CAPELO, M. Regina C. Globalização e Educação. In: Revista Cultural FONTE, Vol 1, $\mathrm{N}^{\circ}$ 1, UNOPAR-Universidade Norte do Paraná, Londrina-Paraná-Brasil, 1998.

SHAFF. Adam. Historia y verdad. Editorial Estampa, Lisboa-Portugal, 1974 .
RAVELO CABRERA, Paul. De la modernidad a la postmodernidad. In: Revista Debates americanos, $\mathrm{N}^{\circ} 2$, juliodiciembre, La Habana, 1996.

- El debate de 10 moderno-postmoderno, Editorial de ciencias sociales, La Habana, 1996. 